\title{
DEPOIMENTOS DE GRANDES MESTRES QUE FAZEM PARTE DA HISTÓRIA DA UFMG
}

Maria de Lourdes Coelho ${ }^{1}$

\section{RESUMO}

Neste artigo, apresentamos os depoimentos de cinco professores aposentados pela Universidade Federal de Minas Gerais (UFMG). Todos eles declararam que o trabalho docente passou a ocupar parte significativa de suas vidas e que não deixaram de ser professores ao se aposentarem. De modo geral, demonstraram-se realizados com a profissão exercida na universidade e destacaram a necessidade de ampliação da discussão sobre a questão da docência como um todo e dos programas de formação de professores universitários.

Palavras-chave: Trabalho docente. Formação de professores. Ensino superior.

${ }^{1}$ Pedagoga na

Universidade Federal de Minas Gerais (UFMG).

\section{INTRODUÇÃO}

"Sucessos do Ofício" foi a denominação dada aos eventos de abertura dos Percursos Formativos em Docência do Ensino Superior oferecidos pela Diretoria de Inovação e Metodologias de Ensino - GIZ, vinculada à Pró-Reitoria de Graduação da Universidade Federal de Minas Gerais (UFMG), com palestras 
de professores que fazem parte da história dessa universidade e que foram convidados a discorrer sobre suas práticas docentes. Os Percursos consistem no programa de formação continuada dos professores iniciantes e veteranos e de formação inicial dos mestrandos e doutorandos que atuavam em atividades de ensino na graduação das diversas áreas da instituição. Os Percursos estão entre as ações do GIZ iniciadas durante o processo de implantação do Programa de Apoio a Planos de Reestruturação das Universidades Federais - REUNI (BRASIL, 2007). A oferta do programa ocorre a cada ano, atendendo, em média, 150 participantes, e tende a continuar, devido à relevante contribuição que presta para repensar a docência na universidade.

Neste artigo, apresentamos os depoimentos de cinco professores aposentados pela UFMG e que foram os palestrantes desses eventos, nos anos de 2010 e 2011. Os conteúdos proferidos pelos cinco palestrantes desses encontros (três, no primeiro, e dois, no segundo) foram transcritos, analisados e apresentados na tese da presente autora, para melhor compreender os modelos de docência praticados em diferentes tempos na UFMG (COELHO, 2012). Devido à relevância dos depoimentos, com a narrativa sobre as práticas docentes exemplares, julgamos pertinente apresentálos a seguir.

\section{O PRIMEIRO EVENTO “SUCESSOS DO OFÍCIO”}

O evento "Sucessos do Ofício", ocorrido em 23 de março de 2010, teve como primeiro palestrante o professor Carlos Roberto Jamil Cury. Graduado em Filosofia, dedicou- 
se aos estudos educacionais em instituições nacionais e internacionais. Como docente, atuou na pós-graduação da Faculdade de Educação da UFMG, no período de 1978 a 1999, além de ocupar cargos na administração e na direção dessa unidade. Prosseguiu como professor e pesquisador na PUC Minas, junto ao programa de pós-graduação. Como especialista em políticas públicas educacionais no Brasil, foi dirigente da Coordenação de Aperfeiçoamento de Pessoal de Nível Superior (CAPES) e do Conselho Nacional de Educação, além de ter participado do processo de transição da antiga para a atual Lei de Diretrizes e Bases, na condição de presidente da Câmara de Educação Básica do Conselho Nacional de Educação (CURY, 2004).

O referido professor iniciou a palestra com o gesto de apontar a bandeira da UFMG exposta no palco do auditório da Reitoria e ler a expressão que nela se encontra: incipit vita nova ("começa uma vida nova"), como algo que fez sentido para aquele evento. Então, declarou, em nome também dos dois outros professores que compuseram a mesa do evento, que, apesar de estarem aposentados, não deixaram de ser professores. Naquele momento, dirigiu-se aos professores iniciantes presentes no auditório e afirmou que eles, ao ingressarem na carreira docente, começaram uma vida nova. Em seguida, revelou o desejo de que os depoimentos trazidos por eles, palestrantes, contribuíssem para a reflexão sobre a trajetória profissional encetada, na qual a docência ocupa um lugar e um tempo precioso no estabelecimento do elo mais direto entre professores e estudantes. Na opinião de Carlos Roberto Jamil Cury, o professor só é professor porque há estudantes. Só há instituição de ensino porque existe aluno, 
e isso é aplicável estritamente à instituição pública. Afirmou, ainda, que o fundamento da instituição escolar pública não é o professor, é o aluno, e explicou:

Por que ele tem o direito de aprender e nós temos o dever de ensinar. E é esse o princípio da escola pública, exatamente o oposto da escola privada. A escola privada assim o é, porque ela diz que, por ser particular, ela também tem a liberdade de ensinar, mas a escola pública, não. A escola pública se assenta no direito de aprender do estudante, seja ele da educação infantil, seja ele da pós-graduação. Então, a função que vocês estão assumindo é uma função que, na atual constituição federal, teve uma mudança significativa. As antigas constituições diziam de um capítulo do funcionário público, ou do funcionalismo público. Mudou a concepção. Mudou para serviço público. Mudou para servidor público. Aquele que serve o direito de aprender do estudante no âmbito institucional, regido pelo MEC. Esse direito de aprender do aluno é que é a nossa responsabilidade maior (informação verbal) ${ }^{1}$.

O professor Carlos Cury chamou a atenção para a responsabilidade do professor universitário em formar futuros cidadãos, pessoas que assumirão um cargo profissional na vida cotidiana. Recordou o início da própria carreira docente, quando vivenciou uma experiência única, que foi passar pelo ciclo básico, implantado na UFMG após a Reforma Universitária de 1968, e teve a oportunidade de aprender com os colegas de outras áreas do conhecimento. A concepção, o planejamento e a avaliação eram preparados juntos, e os professores

${ }^{1}$ Depoimento do professor Carlos Roberto Jamil Cury no evento "Sucessos do Ofício", no auditório da Reitoria da UFMG, em 23 de março de 2010. 
separavam-se dos pares somente quando entravam na sala de aula. Para ele, o trabalho em equipe deve ser resgatado, pois a revolução do mundo contemporâneo e a decorrente interdisciplinaridade não concebem mais o professor fechado em compartimentos. A atual legislação educacional diz que o projeto pedagógico é o símbolo da autonomia da instituição e esta não é constituída por uma pessoa, mas por um corpo docente. Cury defendeu: "não entramos sozinhos nas unidades de ensino que compõem a universidade, pois fazemos parte de um corpo de conhecimento e, portanto, essa interlocução entre as distintas áreas do conhecimento faz com que o professor saia de uma certa compartimentalização" (informação verbal)².

A segunda palestrante, Yara Tupynambá Gordilho Santos, formou-se em Artes Plásticas e estudou no Pratt Institute de Nova lorque. Foi professora e diretora da Escola de Belas Artes da UFMG e professora na Escola Guignard, em Belo Horizonte. Suas obras artísticas são conhecidas nacional e internacionalmente. Algumas estão expostas na UFMG, como o mural “Inconfidência Mineira”, elaborado entre 1968 e 1969, que se encontra no saguão da Reitoria da instituição, conforme mencionado na palestra (ESCRITÓRIO DE ARTE, 2011).

A professora Yara Tupynambá iniciou o depoimento com a distinção entre professores e mestres: professor é aquele que transmite conhecimento técnico e teórico; o mestre vai além da transmissão do conhecimento, pois promove a inserção

2 Depoimento do professor Carlos Roberto Jamil Cury no evento "Sucessos do Ofício", no auditório da Reitoria da UFMG, em 23 de março de 2010.. 
do aluno na vida. Por isso, ela afirmou que teve mestres. Da trajetória discente na universidade, durante a década de 1960, recordou um dos mestres que teve que, na avaliação de Tupynambá, venceu todas as barreiras materiais para dar aulas. De acordo com ela, "generosa e humanamente, ele (o professor) havia se distribuído a todos nós, estudantes" (informação verbal) ${ }^{3}$. Recordou-se, também, de dois outros mestres que, segundo a artista plástica, além de professores, "se davam como pessoas humanas" (informação verbal) 4 .

A terceira palestrante do evento, a professora Beatriz Alvarenga Álvares, foi a primeira mulher a formar-se em Engenharia Civil pela então Universidade de Minas Gerais. Ela exerceu a docência na UFMG com dedicação ao ensino de Física e, depois de aposentar-se, tornou-se professora emérita da instituição. Na ocasião do "Sucessos do Ofício", a docente desenvolvia trabalho voluntário que consistia em receber, no próprio escritório, alunos, professores e curiosos interessados em aprender os fenômenos da natureza. Publicou, em parceria com o professor Antônio Máximo, o livro Curso de Física, considerado obra fundamental no ensino dessa ciência (CRISTO, 2013).

Beatriz Alvarenga deu o testemunho de como o conteúdo da área de conhecimento em que atua fez parte da vida dela e de como o "ser professor" permanece em sua prática cotidiana, mesmo depois de aposentada. Assim sendo, comparou a

${ }^{3}$ Depoimento da professora Yara Tupynambá Gordilho Santos no evento "Sucessos do Ofício", no auditório da Reitoria da UFMG, em 23 de março de 2010.

${ }^{4}$ Ibidem. 
docência com o vício da cachaça e se declarou apaixonada pelo que faz. Relatou que, ao atender professores da educação básica no escritório, busca trabalhar o gosto pelo ensino e o jeito de aproximar a Física do conhecimento vivido pelos alunos, para que compreendam e não apenas decorem fórmulas. Além disso, apresentou objetos que oferecem possibilidades de se ampliar um pouco o conhecimento exclusivo do livro didático, que, na avaliação da docente, geralmente é muito árido. Defendeu também que o ensino deve ser mudado não só no Brasil, pois outros países cometem os mesmos erros em relação a isso, e declarou-se esperançosa ao afirmar que o mundo todo está em processo de mudança para melhor (informação verbal) ${ }^{5}$.

Após as palestras, houve um tempo destinado a perguntas do público e a debates entre os participantes. Esse momento estendeu-se até a semana seguinte ao evento, no fórum que foi aberto em ambiente virtual, no qual todos estavam inseridos e que teve o devido acompanhamento da equipe de tutores do GIZ. Nas mensagens encaminhadas ao fórum de discussão, percebemos o quanto os depoimentos influenciaram os pontos de vista sobre a docência dos participantes. Foi unânime a avaliação positiva do evento e, em muitos comentários, surgiram algumas expressões utilizadas pelos palestrantes. 0 termo "cachaça" apareceu várias vezes na discussão, devido à provocação feita pela professora Beatriz Alvarenga durante a palestra. Alguns concordaram com a comparação feita entre a docência e o vício da cachaça. Um dos participantes do

${ }^{5}$ Depoimento da professora Beatriz Alvarenga Álvares no evento "Sucessos do Ofício", no auditório da Reitoria da UFMG, em 23 de março de 2010. 
fórum virtual afirmou que até tentou deixar a profissão, mas já se sentia viciado no ato de ensinar. As opiniões contrárias associaram a comparação a algo negativo, como a de um participante que, incomodado com o termo, defendeu que "a docência, antes de ser um vício, é uma profissão que deve ser tratada e valorizada como tal”'

\section{O SEGUNDO EVENTO “SUCESSOS DO OFÍCIO”}

Durante o segundo evento "Sucessos do Ofício", houve depoimento de dois outros palestrantes. O primeiro foi o da professora Maria Antonieta Pereira, doutora em Estudos Literários pela Faculdade de Letras da UFMG, que se aposentou em 2007, mas prosseguiu com o desenvolvimento de ensino e de pesquisas na área, com dedicação aos ensinos básico e superior, nos quais atuava antes de ingressar como docente na UFMG. Verificamos que as experiências anteriores da docente influenciaram significativamente na sua forma de perceber as necessidades do aluno.

Maria Antonieta sugeriu que, antes de se entender o que é ser professor universitário, deve-se refletir sobre o que significa "aluno". Recordou a origem da palavra, derivada do latim, do verbo alère, que significa fazer aumentar, crescer, desenvolver, nutrir, alimentar e criar. Outra ideia que ela desenvolveu foi a de rede, por meio da qual, somada à primeira, direcionava o trabalho que realizava na UFMG. Usou a imagem de rizoma como algo que inspira a pensar, por exemplo, nas conexões

${ }^{6} \mathrm{O}$ fórum ocorreu na plataforma adotada pela UFMG para atividades a distância, com acesso restrito aos inscritos nos cursos. 
necessárias, para que o professor consiga desenvolver a contento as tarefas educacionais. Relatou que trabalhava com teorias de rede, presentes hoje nos campos mais avançados da Ciência. Nas práticas exercidas por ela na universidade, declarou que passou a pensar na educação como um hipertexto, que é uma teoria de rede. A partir daí, considera o ensino e a aprendizagem como "um processo que tem que ser nutrido o tempo todo, e o aluno não é apenas aquele que precisa receber o leite materno, o leite do saber. Mas ele é também aquele que provoca esse leite" (informação verbal)7. Sendo assim, não avalia o aluno como uma figura passiva, pois é por causa dele que toda instituição chamada universidade é construída e mantida. Daí, para ela, o processo ensino-aprendizagem é extremamente delicado, de grande potência e ocorre por excelência na universidade. Embora tenha considerado que o conhecimento esteja disseminado na sociedade como um todo, afirmou que "é no seio da universidade que se criam condições para que essas pesquisas educacionais se expandam pela humanidade. Ela não é o único, mas é o lugar em que, por excelência, a sociedade organiza seu pensamento, seu fazer e as formas mais avançadas de viver" (informação verbal) ${ }^{8}$.

O último palestrante, Paulo Roberto Saturnino Figueiredo, sociólogo e pós-graduado em Comunicação Social, exerceu a docência na Faculdade de Filosofia, Ciências e Letras da UFMG, ao mesmo tempo em que exercia atividades administrativas, como diretor, nessa mesma unidade, até aposentar-se, em

7 Depoimento da professora Maria Antonieta Pereira no evento "Sucessos do Ofício", no auditório da Reitoria da UFMG, em 25 de março de 2011.

${ }^{8}$ Ibidem. 
meados da década de 1990. Ele declarou que a fonte da juventude que o alimentava era o relacionamento constante com os alunos, "o renascer que se vive com cada turma, com cada grupo, cada brilho do olhar, cada curiosidade e cada pessoa" (informação verbal) ${ }^{9}$. Declarou que a UFMG se tornou a vida dele, desde que entrou para a instituição, em 1969, pois lá passou grande parte do tempo, como estudante, com estágio, monitoria, e a ministrar aulas, o que avaliou como uma iniciativa inovadora e exótica daquela época. Fez parte de um grupo que iniciou a discussão sobre a questão da docência que, segundo ele, "era vivida por muitos de forma individual, heroica e pessoal" (informação verbal) ${ }^{10}$.

Como profissional, Paulo Saturnino avaliou que teve uma vida muito ativa e ocupou-se, durante 14 anos, com a questão da administração universitária em atividades diversas, porém sem parar de dar aula. Declarou que sente saudade não do poder, nem do cotidiano, mas dos alunos, principalmente da relação com eles. Nas palavras do professor: "Eu acho que esse sentimento vem de uma vocação, de um desejo, de uma integração. É uma disponibilidade que a gente passa a ter para o outro" (informação verbal) ${ }^{11}$. Afirmou que, com a utilização das redes sociais na internet, tem reencontrado progressivamente, a cada dia, mais alunos, que Ihe mandam projetos, pedem opinião. Sente-se recompensado e considerou que isso lhe faz sentir que a docência valeu a pena, além de

\footnotetext{
${ }^{9}$ Depoimento do professor Paulo Roberto Saturnino Figueiredo no evento "Sucessos do Ofício", no auditório da Reitoria da UFMG, em 25 de março de 2011.

${ }^{10}$ Ibidem.

${ }^{11}$ Ibidem.
} 
dar-Ihe sentimento de sucesso, pois permite que constate que a relação com os alunos não se esgotou, mesmo tendo parado de atuar há dez anos.

Assim como no depoimento de Yara Tupynambá, tratado anteriormente, esse palestrante afirmou que a atuação docente que desenvolveu foi espelhada, em parte, em antigos mestres, descritos por ele como "heroicos, humanistas, que chegavam e davam suas aulas fantásticas" (informação verbal) ${ }^{12}$. Recordouse de um professor em especial que, segundo ele, "era um erudito, um livre pensador", que se destacou pela criatividade com que organizava as aulas, a partir de algo como, por exemplo, a utilização de um quadro de Leonardo Da Vinci, para trabalhar a ideia de perspectiva do pensamento político. Ao lembrar-se dos professores que teve, destacou algumas características dos docentes da universidade, na década de 1970, da seguinte forma:

Boa parte dos professores vinha de instâncias diversas da sociedade e de outras práticas, e eles usavam uma parte do seu tempo dando aula. Um era advogado, jornalista, e traziam (sic) essa prática, falavam (sic) ao mundo de sua prática, muitos eram livres pensadores, e possuíam uma erudição que hoje não existe naquela forma. Na Medicina havia os grandes médicos que iam lá e davam um, dois, três cursos, os advogados também largavam o Fórum por um tempo, a profissionalização era muito intensa na universidade (informação verbal) ${ }^{13}$.

\footnotetext{
12 Depoimento do professor Paulo Roberto Saturnino Figueiredo no evento "Sucessos do Ofício", no auditório da Reitoria da UFMG, em 25 de março de 2011.

${ }^{13}$ Ibidem.
} 
Afirmou, então, que a própria formação foi espelhada, em parte, nessa geração, nesses grandes mestres e, em parte, no desejo que o fazia realizar uma psicologia social, por meio de um grupo estruturado, tentando novos processos pedagógicos, nova relação com os alunos. Porém, segundo Paulo Saturnino, na condição de diretor, vivenciou o "atropelamento" de tal geração por novos valores, posturas e exigências que surgiram com o tempo, como a carreira docente na universidade. $\mathrm{Na}$ análise que apresentou, essa transformação foi cruel e, ao mesmo tempo, necessária, pois na universidade não havia reflexão nem preparação para se fazer essa transição. Muitos daqueles personagens simplesmente não conseguiram suportar aquela realidade, a perda do lugar que eles ocupavam, com a chegada à universidade de novos personagens, mais jovens, titulados, surgidos de concursos mais universalizados e democráticos.

Conforme o professor, esses jovens se candidatavam segundo os critérios dos editais e iniciavam a docência universitária sem ter vivência profissional, sem preparo para o ensino, porém mais aptos para receber financiamentos, para responder a vários questionários vindos das agências. Para ele, "a convivência com a nova geração de professores titulados introduziu uma variável extremamente dolorosa e que dificultou muito essas relações" (informação verbal) ${ }^{14}$. Na opinião de Paulo Saturnino, essa geração foi formada por alunos que saíram da graduação e foram direto para a pós-graduação, fizeram mestrado e doutorado, entraram numa realidade com a qual nunca tinham

\footnotetext{
${ }^{14}$ Depoimento do professor Paulo Roberto Saturnino Figueiredo no evento "Sucessos do Ofício", no auditório da Reitoria da UFMG, em 25 de março de 2011.
} 
convivido e, muitas vezes, "alcançavam um status e cargos na estrutura política da universidade muito mais altos do que quem ali estava" (informação verbal) ${ }^{15}$. Assim, considera que tudo isso fez com que, progressivamente, o ensino na graduação deixasse de ser o alvo central e passasse a ocupar um lugar menos nobre e secundário para os docentes.

Ao avaliar o momento de implantação da Reforma Universitária de 1968, ocorrida no meio da ditadura militar, o palestrante descreveu a criação do ciclo básico como "uma perspectiva avançadíssima, que foi de se trazer uma formação humanista, crítica, sólida, ao se possibilitar para as jovens gerações de alunos de diversas áreas, uma postura crítica diante da realidade da época" (informação verbal) ${ }^{16}$. Conforme afirmou, com as conjunturas políticas departamentais implantadas, o ensino das disciplinas básicas "passou por certa crise, que se aprofundou e se tornou algo extremamente problemático" (informação verbal) ${ }^{17}$. Foram contratados professores com perfis específicos, mas muitos desses, conforme o palestrante avaliou, dentro da estrutura departamental, "se encaminharam para as tentações de disputar cargos e financiamentos de pesquisas" (informação verbal) ${ }^{18}$. Com isso, o ciclo básico passou a ser designado aos professores "encostados e problemáticos, com os quais os departamentos não sabiam

${ }^{15}$ Depoimento do professor Paulo Roberto Saturnino Figueiredo no evento "Sucessos do Ofício", no auditório da Reitoria da UFMG, em 25 de março de 2011.
${ }^{16}$ Ibidem.
17 Ibidem.
${ }^{18}$ Ibidem . 
o que fazer" (informação verbal) ${ }^{19}$. Segundo ele, aqueles docentes tinham apenas uma ideia geral do curso e baseavam o ensino das disciplinas naquilo que tinham vontade de fazer, ou no que se sentiam aptos, e cabia aos alunos a tarefa "de tentar juntar os cacos, e tirar daquilo algo que pudesse ser uma formação" (informação verbal) ${ }^{20}$. Consoante a análise de Paulo Saturnino, tudo isso gerou crises e progressivos desinteresses dos alunos.

O docente declarou também que "viveu como professor e administrador - uma fronteira muito tênue entre uma coisa que é indisciplina e uma coisa que é a liberdade de cátedra" (informação verbal) ${ }^{21}$. Para ele, "as pessoas usavam a sua própria indisciplina, a qualquer resquício de um projeto denso coletivo, em nome da liberdade de ensino, da liberdade de cátedra" (informação verbal) 22 .

Em meio às mudanças feitas na universidade, durante a ditadura militar, o palestrante mencionou outras ocorridas em várias instâncias da sociedade. Como exemplo, citou a pesquisa, que passou a ser realizada nas empresas, e a extensão, que era específica da universidade, encontrou também variantes na sociedade, em organizações não governamentais (ONG). Mas defendeu que o ensino não encontrou nem vai encontrar na sociedade esse espaço que se dá na universidade. Porque,

\footnotetext{
${ }^{19}$ Depoimento do professor Paulo Roberto Saturnino Figueiredo no evento "Sucessos do Ofício", no auditório da Reitoria da UFMG, em 25 de março de 2011.

${ }^{20}$ Ibidem.

${ }^{21}$ Ibidem.

${ }^{22}$ Ibidem.
} 
segundo Paulo Saturnino, as empresas não dão ensino, dão treinamento, a partir de um pragmatismo, de objetivos imediatos, para executar tarefas imediatas, segundo regras, sem espaço para reflexão. "Porque isso, pra empresa, é antieconômico. E a universidade tem que ser, por definição, antieconômica, ela não pode trabalhar com a economia que a sociedade ou a empresa ou outras instâncias colocam para ela" (informação verbal) ${ }^{23}$. Para ele, a universidade tem que ser o lugar da polêmica e da diversidade.

Quanto à atuação do professor universitário, o palestrante deixou sugestões relevantes, como descritas a seguir:

Quanta energia se perde pela pouca consideração da dimensão teatral da atividade docente. A atividade docente é uma atividade teatral, não é uma atividade natural. Não é como a relação com uma criança que mama, que é natural. É uma atividade cultural, montada. Do mesmo jeito que um ator tem que aprender a atrair a sua plateia, e que não adianta só ter o cenário, pois esse relacionamento passa pela questão da comunicação dada à ação. Isso dentro da universidade soava um pouco exótico. Falar dessa dimensão teatral é fundamental, do relacionamento com o outro e que dessa relação pra ter um conhecimento, tem que conhecer as regras. Porque se eu faço uma pequena pausa, eu desperto a curiosidade, as pessoas ficam atentas. Se essa pausa fica muito longa, as pessoas ficam inquietas, se eu estico um pouco mais, elas levantam e vão embora. São ritmos. Ninguém tem que ser um ator. As pessoas, em princípio, deveriam ter uma vocação, um desejo pela docência e um respeito por

${ }^{23}$ Depoimento do professor Paulo Roberto Saturnino Figueiredo no evento "Sucessos do Ofício", no auditório da Reitoria da UFMG, em 25 de março de 2011. 
essa atividade e saber que está convivendo em um cenário específico, socialmente construído, onde o professor é um ator insubstituível naquela arte (informação verbal) ${ }^{24}$.

O palestrante concluiu que, ao se considerar a relação docente como não natural, tem-se que pensar também que ela tem de ser construída e reconstruída, numa sequência tensa e permanente, porque os atores-professores mudam, vêm de um mundo diferente, da mesma forma que os atores-alunos, que vêm também de momentos históricos distintos, diante de informações diferentes, e cabe aos professores estar, de alguma forma, prontos para fazer desse encontro algo produtivo e merecedor de "reflexão tão aguda quanto os próprios conteúdos que vão ser dados" (informação verbal) ${ }^{25}$. Diante disso, a docência foi retratada por ele da seguinte forma:

A docência exige, de alguma forma, vocação, talento e dedicação. É sempre mais que uma arte intuitiva, ela não é só uma arte intuitiva e nunca pode se esgotar numa transmissão mecânica de saber. Ela sempre se dará num quadro de valores educacionais relevantes numa sociedade que deve respeitá-los e/ou revolucioná-los. O que eu quero dizer com isso? O professor tem que saber qual o lugar que ocupa naquilo que é o processo de educação. Que lugar ocupa num grande painel daquilo que é o processo de educação no tempo. Quem sou eu, o que é a universidade, quem ela recebe? Quem são esses alunos? De onde eles vêm, como eles veem?

\footnotetext{
${ }^{24}$ Depoimento do professor Paulo Roberto Saturnino Figueiredo no evento "Sucessos do Ofício", no auditório da Reitoria da UFMG, em 25 de março de 2011.

${ }^{25}$ Ibidem.
} 
A docência é o eixo central do processo educacional formal. A sala de aula é o lugar do conhecimento compartilhado e insubstituível. O professor carrega consigo, queira ou não, saiba ou não, sua história de vida e sua visão de mundo. Isso sempre vai com ele para dentro da sala de aula e vai pra relação. Ele não pode e nem deve perder as dimensões ética e política do ato docente. Porque ele chega ali com sua visão do mundo. Ele não deve falsificá-la, ele vai expô-la. Ele é aquela presença, ele tem que ter consciência do seu próprio lugar, da sua própria visão de mundo, dos seus próprios valores, para ele poder relacionar. Por fim, uma questão que parece atravessar todos os planos dos processos educacionais atuais: o temor ao exercício da autoridade. Isso eu acho extremamente grave. Porque o mestre pode e deve ser um bom companheiro. Mas ele não é e não será nessa relação um igual. Muitas vezes ele tenta dissolver até por insegurança. Mas ele não é. Não adianta. Ele não poderá ser, porque estará como que recusando a autoridade que é inerente à sua posição (informação verbal) ${ }^{26}$.

De forma semelhante ao primeiro evento "Sucessos do Ofício", após as exposições dos professores, houve o momento de perguntas aos palestrantes, e o debate sobre a docência prosseguiu no fórum de discussão no ambiente virtual de aprendizagem dos participantes dos Percursos Formativos em Docência do Ensino Superior que ora se iniciava.

\footnotetext{
${ }^{26}$ Depoimento do professor Paulo Roberto Saturnino Figueiredo no evento "Sucessos do Ofício", no auditório da Reitoria da UFMG, em 25 de março de 2011.
} 


\section{CONSIDERAÇÕES FINAIS}

Entre os cinco palestrantes dos dois momentos do evento "Sucessos do Ofício", percebemos o prazer e o gosto pela profissão docente, tanto nas falas quanto nos gestos e no brilho dos olhares. Há uma convergência entre o ponto de vista dos expositores em geral no que se refere ao papel humanístico do professor, que não se restringe ao ensino técnico e teórico. Conferimos o quanto aqueles docentes foram marcados pelos professores que tiveram durante o curso de ensino superior, como mencionado pela professora Yara Tupynambá e pelo professor Paulo Roberto Saturnino. Os depoimentos possivelmente foram significativos para o público em questão, formado por professores iniciantes e veteranos e mestrandos e doutorandos supostamente aspirantes à carreira docente.

A partir desses relatos, destacam-se, com maior ênfase, os elementos que transmitem otimismo e esperança, que aliam o lado profissional ao humanístico do ensino. Foi possível perceber também como o "ser professor" passa a fazer parte da vida pessoal dos professores e como o exercício da docência não se encerra com o término das funções docentes na universidade. Nos dizeres da professora Beatriz Alvarenga, lecionar passa a ser um vício como o da cachaça.

A docência, segundo os referidos palestrantes, ultrapassa o sentido de vocação, talento e dedicação, pois o professor deve ter a capacidade de refletir sobre as próprias ações e assumir o papel central do processo educativo. Os pontos de vista dos docentes que se apresentaram foram ao encontro dos registros das reflexões sobre as experiências apresentadas 
nas discussões que se seguiram nos fóruns virtuais entre os participantes dos Percursos. Os professores palestrantes certamente contribuíram para a formação de muitos que exercem ou exercerão a docência universitária nas próximas décadas, fazendo jus ao nome do evento de que participaram, pois revelaram verdadeiros "sucessos do ofício".

\section{REFERÊNCIAS}

BRASIL. Decreto 6.096 de 24 de abril de 2007. Institui o Programa de Apoio a Planos de reestruturação e Apoio e Expansão das Universidades Federais - REUNI. Brasília: MEC, 2007.

COELHO, Maria de Lourdes. O processo de constituição da docência universitária: o Reuni na UFMG. 2012. 268 f. Tese (Doutorado em Educação: Conhecimento e Inclusão Social) - Faculdade de Educação, Universidade Federal de Minas Gerais, Belo Horizonte, 2012.

CRISTO, Fernanda. Perfil Beatriz Alvarenga: ela desafia a lei da Física. Diversa - Revista da Universidade Federal de Minas Gerais, Belo Horizonte, n. 20, ano 12, abr. 2013.

CURY, Carlos Roberto Jamil. Graduação/pós-graduação: a busca de uma relação virtuosa. Educ. Soc., Campinas, vol. 25, n. 88, p. 777-793, Especial - Out. 2004.

ESCRITÓRIO DE ARTE. Yara Tupynambá. Disponível em <https://www.escritoriodearte.com/artista/yaratupynamba/>. Acesso em: 12 jun. 2011. 
